\title{
Risk Factors for New-Onset Diabetes After Transpant in Kidney Transplant Recipients
}

Authors:
Dana Pramudya, Aditiawardana, Artaria Tjempakasari, Chandra Irwanadi, Nunuk Mardiana, Pranawa, Widodo
Division of Nephrology, Department of Internal Medicine, Dr. Soetomo General Hospital - Faculty of Medicine Universitas
Airlangga, Surabaya, Indonesia
Editor:
Rudi Supriyadi

Received 26 October 2018, revised 10 March 2019, accepted 28 March 2019, published 1 April 2019

\begin{abstract}
Background New-onset diabetes after transplant (NODAT) is one of the metabolic complications of kidney transplant surgery. The incident of NODAT varies highly, from $5 \%$ up to $53 \%$. Some factors increase the risk for NODAT, such as age, gender, immunosuppressant drugs, among others. The progressivity of NODAT leads to increased cardiovascular risks, making the identification of risk factors crucial.

Method Medical records of 56 patients who have undergone kidney transplant throughout 1998 - 2015 were evaluated. Data obtained from the records include age, gender, history of hypertension, dyslipidemia, the use of calcineurin inhibitors (CNI), and familial history of diabetes. Bivariate analysis with crosstabs (for nominal data) was used to analyze the data, with a threshold of $p<0.25$ and followed up with multivariate analysis using logistic regression.
\end{abstract}

Result The mean age of subjects was $53.85 \pm 12.92$ years, with $80.4 \%$ of the subjects were male. Pre-transplant hypertension was $46.4 \%$. The CNI used were tacrolimus in $46.4 \%$ and cyclosporine in $53.6 \%$ of patients. Around $25 \%$ of patients have a familial history of diabetes and the mean triglyceride level was $165.83 \pm 77.5 \mathrm{mg} / \mathrm{dl}$. NODAT occurred in 18 patients and the majority of occurrence happened in the first year post-transplant. Bivariate analysis shows no significant risk factors, however clinically significant risk factors were gender (male), the CNI drug used (tacrolimus), and familial history of diabetes. Further multivariate analysis showed OR for gender (male) with OR 6.532 (0.735$58.051)$, age with OR $5.249(0.658-41.853)\}$, and the use of tacrolimus with OR 3.217 (0.895-11.571).

Conclusion In this study, the clinically significant risk factors for NODAT were male gender, age, and the use of tacrolimus. However, these risk factors did not show statistical significance. Further study with bigger sample size is needed.

Keyword: NODAT, kidney transplant, risk factor
Corresponding author:

Aditiawardana. Division of Nephrology, Department of Internal Medicine, Dr. Soetomo General Hospital - Faculty of Medicine Universitas Airlangga, Surabaya, Indonesia. e-mail: aditiawardana@gmail.com

\section{BACKGROUND}

Chronic kidney disease (CKD) is a global health problem with continually increasing incidence and prevalence and poor outcome, causing a high financial burden. According to the World Health Organization and Burden of Diseases, kidney and urinary tract diseases were responsible for 85,000 of annual death. ${ }^{1}$ Data from the Indonesian Society of Nephrology reported $12.5 \%$ or about 25 million of the Indonesian population have declining renal function or $\mathrm{CKD} .^{2}$

In over 600,000 patients with end-stage renal disease (ESRD) in the United States, a kidney transplant is considered as the most optimum therapy to date. The procedure has been linked to a higher survival rate, better quality of life, and overall lower cost compared to dialysis. ${ }^{3}$

New-onset diabetes after transplant (NODAT) is defined as diabetes that occurred in patients after kidney transplant without a prior history of diabetes. ${ }^{4,5}$ NODAT is one of the least studied complications of kidney transplantation. In a few studies using new immunosuppressant regimen, the prevalence of NODAT is up to $20 \%{ }^{6}$ Diabetes Mellitus (DM) diagnosed after patients underwent organ transplantation is reported in $4 \%-25 \%$ of patients with renal transplantation, $2.5 \%-25 \%$ of patients with liver transplant and $2 \%-53 \%$ of patients with other solid organ transplants. ${ }^{7}$ NODAT increases cardiovascular risks and complication risks such as infection. Moreover, the increase of mortality rate and graft rejection were also found to be associated with 
NODAT. ${ }^{8}$ Risk factors for the development of NODAT can be categorized as non-modifiable and probable modifiable risk factors (Table 1). The interaction between risk factors and its relation to the development of NODAT is presented in Figure 2.

Table 1. Risk factors for NODAT. ${ }^{9}$

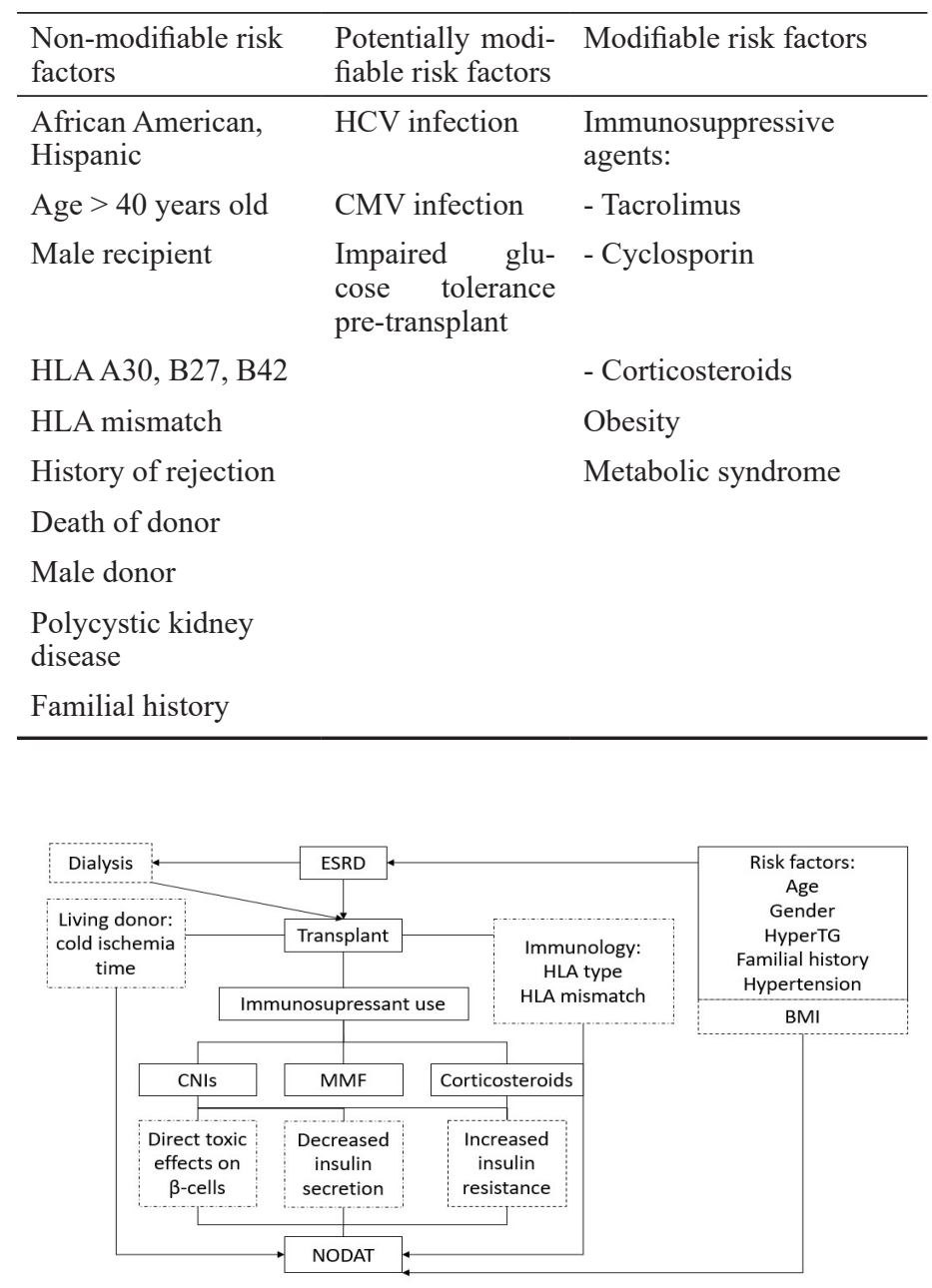

Figure 1. Risk factors for NODAT.

HyperTG: hypertriglyceridemia. Risk factors in dashed boxes were not included in this study.

Because NODAT is linked to poor prognosis in kidney transplant patients, identifying the risk factors for NODAT is of great value. The knowledge will be used to implement preventive measures to decrease the morbidity and mortality rate of kidney transplant patients. Data regarding NODAT risk factors in Indonesia are not yet widely available, therefore this study aimed to identify the risk factors of NODAT in the Indonesian population.

\section{METHODS}

\section{Patients}

Secondary data from medical records were obtained from a private nephrology clinic in Surabaya, consisting of non-diabetic CKD patients who have undergone kidney transplant surgery throughout January 1998 - August 2015 and received immunosuppressant regimen of calcineurin inhibi30 tors (CNI), mycophenolate mofetil (MMF), and methylprednisolone (MP). Medical records not containing adequate clinical information were excluded. A total of 56 patients were found eligible for the study.

\section{Data Collection}

Data related to NODAT risk factors collected were age, gender, history of hypertriglyceridemia, type of CNI drug received, history of hypertension, and familial history of diabetes. NODAT is defined using diagnostic criteria for diabetes mellitus from the American Diabetes Association (2014) in the range of three months after kidney transplantation.

\section{Statistical Analysis}

Data were analyzed statistically using SPSS $22^{\text {nd }}$ version. Qualitative data were presented in the form of sums and percentages, whereas quantitative data were presented as mean values and standard deviations $(\mathrm{X} \pm \mathrm{SD})$. Bivariate analysis using cross tab is used for categorical data and using unpaired T-test or Mann-Whitney. Variables with $\mathrm{p}<$ 0.25 were analyzed using multivariate analysis of logistic regression. Threshold for significant $p$-value is $<0.05$ with $95 \%$ confidence interval.

\section{RESULT}

The subjects consisted of 45 male (80.4\%) and 11 female $(19.6 \%)$ patients, with the mean age of $53.85 \pm 12.92$ years. The event of NODAT occurred in $18(32.1 \%)$ subjects. The subjects receiving tacrolimus were 30 patients $(53.5 \%)$ and the other $26(46.4 \%)$ received cyclosporine. History of prior hypertriglyceridemia was found in 10 subjects $(17.9 \%)$, hypertension in 26 subjects $(46.4 \%)$, and familial history of diabetes in 14 subjects $(25 \%)$. (Table 1$)$.

Table 1. Subjects characteristics

\begin{tabular}{ccc}
\hline Variable & Data & Result \\
\hline Age & Mean & $53.85 \pm 12.92$ years \\
& $\geq 60$ y.o. & $6 / 56(10.7 \%)$ \\
Gender & 60 y.o. & $50 / 56(89.3 \%)$ \\
NODAT & Male & $45 / 56(80.4 \%)$ \\
& Female & $11 / 56(19.6 \%)$ \\
CNI & Yes & $18 / 56(32.1 \%)$ \\
& No & $38 / 56(67.9 \%)$ \\
Triglyceride & Tacrolimus & $30 / 56(53.6 \%)$ \\
& Cyclosporine & $26 / 56(46.4 \%)$ \\
& Mean value & $165.83 \pm 77.5 \mathrm{mg} / \mathrm{dl}$ \\
& HyperTG & \\
Hypertension & Yes & $10 / 56(17.9 \%)$ \\
& No & $46 / 56(82.1 \%)$ \\
Family history of & Yes & \\
diabetes & No & \\
& Yes & \\
\hline & No & \\
& &
\end{tabular}


Bivariate analysis found no significant risk factors for NODAT. However, some variables have clinically significant effects such as age, gender, familial history of diabetes, and the type of calcineurin inhibitors used (Table 2). Data with $\mathrm{p}<0.25$ from bivariate analysis was further analyzed using multivariate analysis, where the risk factors of NODAT included age $\geq 60$ years old (OR 6.532, CI $0.735-58.051$ ), male gender (OR 5.249, CI 0.658-41.853), the use of CNI tacrolimus (OR 3.217, CI 0.895 - 11.571), which, despite OR values $>1$, have a wide range of OR if CI 95\% surpassing the value of 1 , further proves no statistical significance. (Table 3)

Table 2. Bivariate analysis

\begin{tabular}{llll}
\hline Risk Factor & NODAT & $\begin{array}{l}\text { No } \\
\text { NODAT }\end{array}$ & p-value \\
\hline Age & & & \\
$\quad \begin{array}{l}\mathbf{6 0} 0 \text { years old } \\
\quad<\mathbf{6 0} \text { years old }\end{array}$ & 14 & 2 & 0.055 \\
$\begin{array}{l}\text { Gender } \\
\quad \text { Male }\end{array}$ & 17 & 28 & 0.068 \\
$\quad$ Female & 1 & 10 & \\
$\begin{array}{l}\text { Hypertension } \\
\quad \text { Yes }\end{array}$ & & & \\
$\quad$ No & 9 & 17 & 0.712 \\
CNI $\quad$ & 9 & 21 & \\
$\quad$ Tacrolimus & 13 & 17 & 0.093 \\
$\quad$ Cyclosporine & 5 & 21 & \\
HyperTG & & & \\
$\quad$ Male & & 3 & 0.557 \\
$\quad$ Female & 4 & 26 & \\
Family history of Diabetes & & & \\
$\quad$ Yes & 14 & 7 & 0.099 \\
$\quad$ No & 7 & 31 & \\
\hline
\end{tabular}

Table 3. Multivariate analysis

\begin{tabular}{lll}
\hline Risk Factor & $\begin{array}{c}\text { Odds } \\
\text { Ratio }\end{array}$ & Confidence Interval \\
\hline Age $\geq$ 60 years old & 6.532 & $0.735-58.051$ \\
Male gender & 5.249 & $0.658-41.853$ \\
Tacrolimus & 3.217 & $0.895-11.571$ \\
\hline
\end{tabular}

\section{DISCUSSION}

NODAT was first discovered in 1964 from liver transplant patients of Thomas Starz, which developed 6 months after surgery and receiving immunosuppressant therapy. The rate of diabetes in these patients was $6 \%$ annually. ${ }^{11}$ The rate of NODAT incidence varies, depending on the type of organ transplanted, time of follow-up, diagnostic criteria, and immunosuppressant drugs used.

The pathophysiology of NODAT includes the diabetogenic effect of corticosteroids, which is dose-dependent.
A prospective study on 173 kidney-transplant patients, an increase of prednisolone dosage $0.01 \mathrm{mg} / \mathrm{kg} /$ day is related to a $5 \%$ increase in diabetes mellitus. ${ }^{6}$ Corticosteroid was found to alter glucose metabolism by increasing liver glucose production and decreasing insulin sensitivity. Insulin resistance and relative insulin deficiency were suggested to be the main cause of diabetes due to steroid use. Steroid discontinuation protocol showed decreased insulin resistance and increased glucose metabolism in kidney transplant patients. $^{12}$ Decreased insulin secretion was considered as the main contributing factor of calcineurin inhibitors' diabetogenic effect. An experimental study showed calcineurin inhibitors' effect in insulin gene expression of pancreatic beta-cells. Pancreas biopsy showed a relationship between pancreatic islet cells and the blood concentration of tacrolimus and cyclosporine. ${ }^{9}$

The prevalence of NODAT in this study was $32.1 \%$. In a study by Vincenti et al, the prevalence of NODAT 6 months after kidney transplant was $20.5 \%$, whereas the study by Woodward et al found $24.8 \%$ of NODAT prevalence. ${ }^{11,13}$

In this study, the only risk factor found nearing statistical significance was the age of $>60$ years old $(p=0.055)$ similar to study results by Shah et al. Other risk factors that were found clinically significant but not statistically significant were male gender $(\mathrm{p}=0.068)$, consistent to study results conducted by Pham et al. ${ }^{9}$ and the use of tacrolimus $(\mathrm{p}=0.093)$. Clinical trials assessing the effects of tacrolimus and cyclosporine administration in transplant patients showed varying results, but mostly showing higher diabetogenic effects of tacrolimus. Data from the United States showed the incidence of NODAT 2 years after transplant was higher in patients receiving tacrolimus (30\%) compared to those receiving cyclosporine (18\%), suggesting the use of tacrolimus as a risk factor for NODAT compared to cyclosporine. ${ }^{11}$

Familial history of diabetes was found to be a risk factor for NODAT in a study by Hjelsmeeth et al. ${ }^{6}$ In this study however, no relationship was found between family history of diabetes with increased risk for NODAT.

This study has numerous limitations including the small sample size and the use of secondary data from medical records. The sample was also obtained from one private clinic with no regards to the place of surgery. Better recording system and centralization of transplant procedure to one dedicated health center are important to give comprehensive management to transplant patients. Future research should include samples from multiple centers to give a better representation of patients and increase the statistical power of the study.

\section{CONCLUSION}

This study found patients' age of over 60 years old, male gender, and the use of tacrolimus in the immunosuppressive regimen to be a clinically significant but not statistically significant risk factor for NODAT. Bigger multicenter studies with a higher amount of subjects are needed to assess the risk factors of NODAT. 


\section{REFERENCES}

1. Levey A, Coresh J. Chronic Kidney Disease. Lancet. 2012 Jan 14;379(9811):165-80.

2. Perhimpunan Nefrologi Indonesia. Konsensus Manajemen Anemia pada Penyakit Ginjal Kronik. Jakarta: Pernefri; 2011.

3. Patze R, Pastan S. Dialysis Facility and Network Factors Associated With Low Kidney Transplantation Rates Among United States Dialysis Facilities. Am J Transplant. 2014 Jul;14(7):1562-72.

4. Viberti G. Diabetes mellitus: a major challenge in transplantation. Transplant Proc. 2001 Aug;33(5A Suppl):3S-7S.

5. Maskey R. New-Onset Diabetes after Transplant (NODAT) Kathmandu Univ Med J (KUMJ). 2014 Oct-Dec;12(48):301-5.

6. Hjelmesaeth J, Hartmann A, Kosstad J, Egeland T, Stenstrom J, Fauchald P. Tapering off prednisolone and cyclosporine the first year after renal transplantation: the effect on glucose tolerance. Nephrol Dial Transplant. 2001 Apr;16(4):829-35.

7. Davidson J, Wilkinson AH, Dantal J. New-onset diabetes after transplantation: 2003 International Consensus Guidelines. Transplantation. 2003 May 27;75(10 Suppl):SS3-24.

8. Kasiske B, Snyder J, Gilbertson D. Diabetes mellitus after kidney transplantation in the United States. Am J Transplant. 2003 Feb;3(2):178-85.

9. Pham P, Lipshutz G, Wilkinson A. New Onset Diabetes Mellitus After Solid Organ Transplantation. Endocrinol Metab Clin North Am. 2007 Dec;36(4):873-90; vii.

10. Ghisdal L, Laecke S, Abramowichz M. New-onset diabetes after renal transplantation. Diabetes Care. 2012 Jan; 35(1): 181-188.

11. Woodward RS, Schnitzler MA, Baty J. "Incidence and cost of new onset diabetes mellitus among US wait-listed and transplanted renal allograft recipients". Am J Transplant. 2003 May;3(5):590-8.

12. Van Hooff P, Christiaans L, van Duijhoven M. Evaluating mechanisms of posttransplant diabetes mellitus. Nephrol Dial Transplant. 2004 Dec;19 Suppl 6:vi8-vi12.

13. Vincenti F, Friman S, Scheuermann E, Rostaing L, Jenssen T. (2007). Results of an international, randomized trial comparing glucose metabolism disorders and outcome with cyclosporine versus tacrolimus. Am J Transplant. 2007 Jun;7(6):1506-14. 